\title{
Clavicle pain
}

\section{Jing $\mathrm{Wu}^{1} \cdot$ Harrison X. Bai ${ }^{2} \cdot$ Zishu Zhang ${ }^{1}$}

Published online: 21 February 2018

(C) ISS 2018

\section{Discussion}

In the case presented, a 16-year-old male with a history of repeated trauma to his left clavicle complained of intermittent and worsening left clavicular pain for several months. He was found to have a nondisplaced clavicle fracture with marked osteolysis on X-ray (Fig. 1) and worked up for a possible neoplasm. An open intralesional biopsy of the area of bone loss was taken and showed bone trabeculae replaced by fibrous connective tissue (Fig. 2a) and prominent vessels lined by a single layer of endothelial cells (Fig. 2b). No neoplastic, acute inflammatory, or infectious process was identified. One month later, he subsequently underwent open reduction and internal fixation with a major autologous bone graft to stabilize the middle segment of his left clavicle (Fig. 3). Lab values were all within normal limits. The patient was started on bisphosphonate. Seven months later, X-ray showed that several of the medially based screws had loosened with progression of osteolysis (Fig. 4). Four screws were subsequently removed from the left clavicle plate. At 11 months after the initial surgery, the patient had complete removal of the hardware (Fig. 5), since his bone resorption had progressed to a point where his clavicle was difficult to visualize on X-ray. After excluding other causes of osteolysis, such as infection, cancer, inflammatory and endocrine disorders, a final diagnosis of Gorham's disease (GD) was made based on the radiographic and histologic findings.

The case presentation can be found at https://doi.org/10.1007/s00256018-2881-0

\section{Zishu Zhang}

zishuzhang@csu.edu.cn

1 Department of Radiology, The 2nd Xiangya Hospital of Central South University, 139 Renmin Zhong Road, Changsha, Hunan 410011, China

2 Department of Radiology, Hospital of the University of Pennsylvania, 3400 Spruce Street, Philadelphia, PA 19104, USA
GD is a rare idiopathic bone disease characterized by spontaneous and progressive osteolysis and hypervascular and/or angiomatous fibrous connective tissue proliferation without osteoblastic reaction [1]. It does not have race or gender preference, but occurs more frequently in children and young adults. The disease can affect any single bone or multiple bones. The cranium, shoulder, and pelvis are the most common sites [2]. Clinical manifestations vary depending on the site and the extent of involvement. Some patients may present with abrupt pain due to pathologic fracture [3].

The diagnosis of GD is based on radiology and clinicopathology. The X-ray features are similar to those of $\mathrm{CT}$, which can be patchy osteopenia progressing to osseous resorption without sclerosis or osteoblastic reaction. The osteolysis may extend to the contiguous bone and may not spare the intervening joint [4]. Intramedullary or subcortical lucent foci may be the earliest manifestation, with later slowly progressive atrophy, dissolution, fracture, fragmentation, and disappearance of a part of a bone. MRI demonstrates heterogeneously lobulated hyperintensity on T2WI with heterogeneous enhancement, related to the mix of hemorrhage and angiomatous and fibrous tissue [4]. Both CT and MRI are useful in the delineation of the soft tissue extension, and enable biopsy guidance and a surgical plan. Tc- $99 \mathrm{~m}$ bone scintigraphy may demonstrate increased uptake of the radiopharmaceutical agents on the initial images, and subsequently decreased uptake corresponding to the osteolysis [5]. Besides neoplastic, infectious, metabolic osteolysis, differential diagnoses of GD include hereditary osteolysis, generalized lymphatic anomaly (GLA), and nonhereditary osteolysis with neuropathy. Hereditary osteolysis occurs during infancy and commonly involves the hands and feet without vascular changes. Lala et al. found that osteolysis seen in GLA is more insidious. Findings favoring GLA include more extensive involvement, the presence of discrete macrocystic lymphatic malformations, and visceral organ lesions [6].

GD is often progressive but sometimes can be self-limiting [7]. Serious complications are rare, but chylous pericardial and pleural effusions, spinal, and/or visceral involvement 
can be fatal $[8,9]$. Its etiology and pathophysiology remain unclear, and trauma may be the trigger [9]. Current treatment includes anti-osteoclastic medication, interferon, radiotherapy, and surgery [10].

\section{Compliance with ethical standards}

Conflict of interest The authors declare that they have no conflicts of interest.

\section{References}

1. Renacci RM, Bartolotta RJ. Gorham disease: lymphangiomatosis with massive osteolysis. Clin Imaging. 2017;41:83-5.

2. Florchinger A, Bottger E, Claass-Bottger F, Georgi M, Harms J. Gorham-Stout syndrome of the spine. Case report and review of the literature. Rofo. 1998;168(1):68-76.

3. Kilicoglu ZG, Kizildemir KN, Vardar AF, Berkman MZ, Simsek MM. Gorham disease of the craniocervical junction: X-ray, computed tomography, and magnetic resonance imaging findings. Spine J. 2013;13(5):e11-4.
4. Kai B, Ryan A, Munk PL, Dunlop P. Gorham disease of bone: three cases and review of radiological features. Clin Radiol. 2006;61(12): 1058-64.

5. Spieth ME, Greenspan A, Forrester DM, Ansari AN, Kimura RL, Gleason-Jordan I. Gorham's disease of the radius: radiographic, scintigraphic, and MRI findings with pathologic correlation. A case report and review of the literature. Skelet Radiol. 1997;26(11):65963.

6. Lala S, Mulliken JB, Alomari AI, Fishman SJ, Kozakewich HP, Chaudry G. Gorham-Stout disease and generalized lymphatic anomaly-clinical, radiologic, and histologic differentiation. Skeletal Radiol 2013;42(7):917-24.

7. Sa P, Marques P, Oliveira C, Rodrigues AS, Amorim N, Pinto R. Gorham's disease: clinical case. Rev Bras Ortop. 2015;50(2):23942.

8. Kotecha R, Mascarenhas L, Jackson HA, Venkatramani R. Radiological features of Gorham's disease. Clin Radiol. 2012;67(8):782-8.

9. Dellinger MT, Garg N, Olsen BR. Viewpoints on vessels and vanishing bones in Gorham-Stout disease. Bone. 2014;63:47-52.

10. Hu P, Yuan XG, Hu XY, Shen FR, Wang JA. Gorham-Stout syndrome in mainland China: a case series of 67 patients and review of the literature. J Zhejiang Univ Sci B. 2013;14(8):729-35. 